\title{
Dietary transitions and sustainability: current patterns and future trajectories
}

\author{
Alexandros Gasparatos ${ }^{1}$
}

Published online: 8 June 2020

○) Springer Japan KK, part of Springer Nature 2020

\section{Background}

Food systems have major intersections with resource use and environmental change (Willet et al. 2019; Vermeulen et al. 2012; Alexander et al. 2015; IPBES 2019; UNEP 2016). At the same food systems are tightly embedded in practically every society, culture and national economy, catering for the livelihoods of a large fraction of the global population (Oteros-Rozas et al. 2019; Alston and Pardey 2014). However, food systems have been undergoing major transitions globally during the past decades (Reardon and Timmer 2012; HLPE 2017), a trend that is expected to continue and have major ramifications for sustainability (Bene et al. 2019; Caron et al. 2018).

Diets and dietary preferences are a major element of food systems (Zurek 2018; Chaudhary et al. 2018; HLPE 2017; Gouel and Guimbard 2019). Far from being static, dietary preferences change and evolve over time, with different types of dietary transitions having unfolded in the last decades across the world, including shifts to diets richer in animal protein, vegetable oils or processed food (Chang et al. 2018; Popkin 2017). At the same time, dietary transitions are not homogenous, but exhibit very diverse characteristics, drivers and impacts across different geographies, cultures, and levels of economic development and urbanization. For example, the types and drivers of dietary transitions can be relatively different between developed and rapidly developing regions, or between rural and urban areas (Popkin 2017; Pingali 2007; Nisbett et al. 2017).

In fact, drivers as diverse as urbanization, changes in life and working style, changes in income, trade liberalization, and the emergence of different food retailing options all combine in differing degrees to drive dietary transitions

Alexandros Gasparatos

gasparatos@ifi.u-tokyo.ac.jp

1 Institute for Future Initiatives (IFI), University of Tokyo, Tokyo, Japan in different global contexts (Kearney 2010; HLPE 2017). However, it is not always straightforward to capture and analyze properly such transitions, especially in low and middleincome countries (Walls et al. 2018). In a similar fashion, dietary transitions can have a large array of sustainability impacts on health, environment, and socioeconomic conditions (Aleksandrowicz et al. 2016; Springmann et al. 2016; Milner et al. 2017), which can manifest through very different and converging mechanisms (Tilman and Clark 2014; Hallstrom et al. 2015; Eker et al. 2019).

Many scholars have suggested that steering dietary transitions towards more sustainable pathways will be an essential element of broader sustainability transitions (Willet et al. 2019; El-Bilali et al. 2019). However, the policy options and practical solutions to foster sustainable dietary transitions would most likely be different across different global contexts, requiring the combination of various instruments and interventions (Willet et al. 2019; HLPE 2017).

\section{Aims and scope}

The above suggest that dietary changes and transitions have multiple interconnected elements that intersect strongly with sustainability at different scales. At the same time, these elements and interconnections can be highly varied across different global contexts. It is thus important to adopt interdisciplinary and trans-disciplinary research approaches to both understand the interface of dietary transitions and sustainability, as well as to design appropriate responses for steering these transitions to more sustainable pathways (Willet et al. 2019; HLPE 2017).

Sustainability science is ideal for exploring this interface between dietary transitions and sustainability due to its question-driven and solutions-oriented approach, and its ability to link social and ecological systems, and different knowledge systems (Kates 2011; Komiyama and Takeuchi 2006). 
This special feature will consist of papers that use approaches anchored in sustainability science to explore one of more of the following questions:

1 Type and characteristics of dietary transitions in different geographies, cultures and societies, and levels of economic development and urbanization;

2 Drivers of dietary transitions, and their relation to broader demographic, socioeconomic, cultural, and environmental processes;

3 Sustainability impacts of dietary transitions in different geographies, cultures and societies, and levels of economic development and urbanization;

4 Mechanisms, processes and impacts mediating the reconfiguration of food systems in the face of dietary transitions;

5 Future scenarios and pathways of dietary transitions, and their interaction with sustainable development;

6 Tools, methods and models for unraveling dietary transitions and their drivers and impacts;

7 Policy and practice approaches to steer dietary transitions to more sustainable pathways in difference contexts.

All selected manuscripts should reflect two elements (a) dietary transitions or changes (i.e., not simply static dietary preferences or choices) and (b) clear links to sustainability. Submissions that do not articulate clearly in the abstract and final manuscript the transition/change aspects and their interface with sustainability will not be considered.

\section{Timeline}

Interested authors should submit extended abstracts to the Special Feature editor by 15 August 2020. The abstracts should be $500-750$ words and contain the names of all authors and information about the methodology, case studies (if any), results and link to sustainability. Upon acceptance authors will be invited to submit full manuscripts through the journal's electronic editorial management system, keeping in mind publisher formatting guidelines and length requirements. Most manuscripts should fall within the following categories: original articles, technical reports and case reports. A few high quality review articles and overview articles will be considered in coordination with the special feature editor.

Interested authors should make inquiries and submit extended abstracts to: gasparatos.alex@gmail.com and/or gasparatos@ifi.u-tokyo.ac.jp

Open abstract call: until 15 August 2020

Abstract acceptance/Paper invitation: late August 2020
First draft submission through EM system: by 31 December 2020

First review: January-February 2021

Revised submissions: by April 2021

Second review (if needed): May-June 2021

Final decision: by September 2021

\section{References}

Aleksandrowicz L, Green R, Joy EJM, Smith P, Haines A, Wiley AS (2016) The impacts of dietary change on greenhouse gas emissions, land use, water use, and health: a systematic review. PLOS ONE 11(11):e0165797

Alexander A, Rounsevell MAD, Dislich C, Dodson JR, Engström K, Moran D (2015) Drivers for global agricultural land use change: the nexus of diet, population, yield and bioenergy. Glob Environ Change 35:138-147

Alston JM, Pardey PG (2014) Agriculture in the global economy. J Econ Perspect 28:121-146

Béné C, Oosterveer P, Lamotte L, Brouwer ID, de Haan S, Prager SD, Talsma EF, Khoury CK (2019) When food systems meet sustainability: current narratives and implications for actions. World Dev 113:116-130

Caron P, de Loma-Osorio GF, Nabarro D et al (2018) Food systems for sustainable development: proposals for a profound four-part transformation. Agron Sustain Dev 38:41. https://doi.org/10.1007/ s13593-018-0519-1

Chang X, DeFries RS, Liu L, Davis K (2018) Understanding dietary and staple food transitions in China from multiple scales. PLoS ONE 13:e0195775

Chaudhary A, Gustafson D, Mathys A (2018) Multi-indicator sustainability assessment of global food systems. Nat Commun 9:848

Eker S, Reese G, Obersteiner M (2019) Modelling the drivers of a widespread shift to sustainable diets. Nat Sustain 2:725-735

El-Bilali H, Callenius C, Strassner C, Probst L (2019) Food and nutrition security and sustainability transitions in food systems. Food Energy Secur 8:e00154

Gouel C, Guimbard H (2019) Nutrition transition and the structure of global food demand. Am J Agric Econ 101:383-403

Hallström E, Carlsson-Kanyama A, Börjesson P (2015) Environmental impact of dietary change: a systematic review. J Clean Prod 91:1-11

HLPE (2017) Nutrition and food systems. High level panel of experts on food security and nutrition. Committee on World Food Security, Rome

IPBES (2019) Global assessment report on biodiversity and ecosystem services of the Intergovernmental Science-Policy Platform on Biodiversity and Ecosystem Services. IPBES Secretariat, Bonn

Kates RW (2011) What kind of a science is sustainability science? Proc Natl Acad Sci 108:19449-19450

Kearney J (2010) Food consumption trends and drivers. Philos Trans R Soc B 365:2793-2807

Komiyama H, Takeuchi K (2006) Sustainability science: building a new discipline. Sustain Sci 1:1-6

Milner J, Joy EJM, Green R, Harris F, Aleksandrowicz L, Agrawal S, Smith P, Haines A, Dangour AD (2017) Projected health effects of realistic dietary changes to address freshwater constraints in India: a modelling study. Lancet Planet Health 1:e26-e32

Nisbett N, van den Bold M, Gillespie S, Menon P, Davis P, Roopnaraine T, Kampman H, Kohli N, Singh A, Warren A (2017) Community-level perceptions of drivers of change in nutrition: 
evidence from South Asia and sub-Saharan Africa. Glob Food Secur 13:74-82

Oteros-Rozas E, Ruiz-Almeida A, Aguado M, González JA, RiveraFerre MG (2019) A social-ecological analysis of the global agrifood system. Proc Natl Acad Sci 116:26465-26473

Pingali P (2007) Westernization of Asian diets and the transformation of food systems: implications for research and policy. Food Policy 32:281-298

Popkin BM (2017) Relationship between shifts in food system dynamics and acceleration of the global nutrition transition. Nutr Rev $75: 73-82$

Reardon T, Timmer CP (2012) The economics of the food system revolution. Annu Rev Resour Econ 4:225-264

Springmann M, Godfray HCJ, Rayner M, Scarborough P (2016) Analysis and valuation of the health and climate change co-benefits of dietary change. Proc Natl Acad Sci 113:4146-4151

Tilman D, Clark M (2014) Global diets link environmental sustainability and human health. Nature 515:518-522

UNEP (2016) Food Systems and Natural Resources: a report of the working group on Food Systems of the International Resource Panel. United Nations Environment Programme (UNEP), Nairobi
Vermeulen SJ, Campbell BM, Ingram JSI (2012) Climate change and food systems. Annu Rev Environ Resour 37:195-222

Walls HL, Johnston D, Mazalale J, Chirwa EW (2018) Why we are still failing to measure the nutrition transition. BMJ Global Health 3:e000657

Willet et al (2019) Food in the Anthropocene: the EAT-Lancet Commission on healthy diets from sustainable food systems. Lancet 393(10170):447-492

Zurek M, Hebinck A, Leip A, Vervoort J, Kuiper M, Garrone M, Havlík P, Heckelei T, Hornborg S, Ingram J, Kuijsten A (2018) Assessing sustainable food and nutrition security of the EU food system: an integrated approach. Sustainability 10:4271

Publisher's Note Springer Nature remains neutral with regard to jurisdictional claims in published maps and institutional affiliations. 